\title{
EFICÁCIA DE DIFERENTES TIPOS DE ESCOVAS DENTAIS NA REMOÇÃO DO BIOFILME BUCAL
}

\author{
Ana Carolina Soares Fraga Zaze ${ }^{1}$ \\ Edimar Rafael de Oliveira ${ }^{2}$ \\ Maria de Jesus Andrade da Silva Melão \\ Ederson Alves ${ }^{2}$
}

\begin{abstract}
ZAZE, A. C. S. F.; OLIVEIRA, E. R. de; MELÃO, M. de J. A. da S.; ALVES, E. Eficácia de diferentes tipos de escovas dentais na remoção do biofilme bucal. Arq. Cienc. Saúde UNIPAR, Umuarama, v. 20, n. 2, p, 101-109, maio/ago. 2016.

RESUMO: Devido ao fato de o método mais indicado para remoção do biofilme bucal ser o mecânico, com a utilização da escova dental, buscou-se verificar as características das escovas dentais mais eficazes. Foram avaliadas as seguintes características: relação entre cabo haste e cabeça, com o intuito de verificar angulações, formato e tipo das cerdas, considerando tamanho e disposição dos tufos, bem como comparar a eficácia das escovas manuais e elétricas. O estudo foi realizado com 28 crianças em uma escola municipal da cidade de Umuarama-PR. Foram utilizados quatro tipos de escovas: escova de haste reta com cerdas regulares; escova de haste angulada com cerdas regulares; escova de haste angulada com cerdas irregulares e escova elétrica. Foram realizados a evidenciação do biofilme e o Índice de Higiene Oral Simplificado (IHOS) antes e após a escovação. Os diferentes tipos de escovas foram avaliados de acordo com a diferença entre o percentual de biofilme antes e após a escovação, bem como em relação à redução da classificação do IHOS. Nas diferentes análises, a escova de haste reta apresentou os melhores resultados. Em contrapartida, a escova elétrica apresentou resultados menos satisfatórios. Pode-se concluir que todas as escovas dentárias apresentaram potencial de redução do biofilme dentário, independentemente das características de sua haste, cerdas ou manuseio (manual ou elétrico). Contudo, os melhores resultados foram atribuídos à escova que apresenta a haste reta, que também possui cerdas regulares.
\end{abstract}

PALAVRAS-CHAVE: Dispositivos para o cuidado bucal domiciliar. Escovação dentária. Higiene bucal.

\section{EFFECTIVENESS OF DIFFERENT TYPES OF DENTAL BRUSHES IN REMOVAL OF ORAL BIOFILM}

\begin{abstract}
Since the most effective method for the removal of oral biofilm is the mechanical one, with the use of a toothbrush, this study aimed to check the characteristics of the most effective toothbrushes. The following characteristics were analyzed: handle and head ratio, tuft layout, as well as a comparison between manual and electric toothbrushes. This work was conducted with 28 children in a public school in the city of Umuarama/PR. Four types of brushes were used: straight shank brush with regular bristles; angled stem with regular bristles; angled stem with irregular bristles; and electric toothbrush. The disclosure of oral biofilm and the Simplified Oral Hygiene Index (SOHI) before and after brushing were analyzed. The different kinds of brushes were evaluated according to the difference between the percentage of biofilm before and after brushing, as well as the reduction of SOHI. Straight shank brushes showed the best results in different analysis. On the other hand, the electric toothbrush brought the less satisfactory results. It was possible to conclude that all toothbrushes have shown potential for biofilm reduction, regardless of the characteristics of their handles, bristles or usage (manual or electric). However, the best results were attributed to the straight shank brush with regular bristles.
\end{abstract}

KEYWORDS: Dental Devices. Home Care. Oral hygiene. Tooth brushing.

\section{Introdução}

O biofilme dental associado a fatores determinantes e modificadores, é considerado peça chave para o desenvolvimento das principais doenças bucais, ou seja, a cárie dentária e as doenças periodontais (AXELSSON, et al. 1991). É de conhecimento, que a rotina e a eficácia da escovação diária, somadas à frequência desta, controlam o biofilme dentário o suficiente para interferir na sua maturidade microbiológica e limita a severidade das doenças dentárias observadas clinicamente. Segundo Berenie (1973), sabe-se que a qualidade da higiene bucal realizada, uma, duas ou mais vezes ao dia, é suficiente para o controle do biofilme dentário. Contudo, Bellini e colaboradores (1981) observaram que a qualidade da higiene bucal é mais importante que sua frequência. Além disso, Storino (1994) relata que a frequência da higiene deve ser suficiente para prevenir a cárie e a doença periodontal.

Desde a década de 60, quando Loe (1965) demonstrou o papel da placa bacteriana no desenvolvimento da gengivite, ficou evidente a importância do correto controle desta para a saúde dos tecidos bucais. Inúmeros estudos demons- traram que o controle efetivo da placa diminui a prevalência e a incidência das doenças periodontais e cárie (AXELSSON, et al. 1991).

Entre os métodos mais utilizados de controle mecânico da placa supragengival, inclui-se uma escova dental associada ao fio ou fita dental. Os pacientes conseguem remover a placa em até $1 \mathrm{~mm}$ subgengival com uma boa escovação (WAERHAUG, 1981).

As escovas dentais têm importante papel não só no controle da placa bacteriana, mas também na remoção das manchas extrínsecas que se formam sobre a superfície dos dentes pela liberação dos princípios ativos que os dentifrícios contêm (PANZERI, 1993). A eficácia de uma escova em remover biofilme dental está relacionada com o alinhamento de suas cerdas que, com o tempo de uso, apresentam alterações nos diferentes sentidos (para frente, para trás e para os lados) como resultado da pressão exercida contra os dentes (VILANI; BAPTISTA; VERTUAN, 1998). É dever do cirurgião-dentista, ter conhecimento técnico e científico, para saber indicar o melhor tipo de escova de acordo com o perfil do paciente em questão. 


\section{Características da escova dentária manual}

As escovas dentárias apresentam quatro componentes básicos: cabo, haste ou intermediário, cabeça e cerdas. Segundo a Associação Dentária Americana (ADA), a escova ideal deve apresentar certas características, tais como: tufos de cerdas com o mesmo comprimento, cabeça e haste situada no mesmo eixo, leveza e facilidade de limpeza, impermeabilidade à umidade, cerdas de nylon, cabeça pequena, baixo custo, durabilidade e eficiência no controle de placa. Analisando as características morfológicas das escovas dentárias nacionais, Halla (1987) preconizou que as escovas dentárias deveriam apresentar características morfológicas tais como: cabo achatado, comprimento de cabeça de 25 a $32 \mathrm{~mm}$ e largura de 8 a $11 \mathrm{~mm}$, constassem tufos em fileiras de $3 \times 6$ ou $3 \times 8$, as cerdas fossem de nylon com comprimento uniforme, pontas arredondadas e de consistência média com diâmetro entre 0,30 a 0,32. Stabbe (1988), revisando a literatura, afirma que não existem dados conclusivos que comprovem qual o desenho específico de escova dental ou forma que melhor remove a placa dental. Comparando escovas convencionais ou modernas e remoção de placa supra gengival, não se observam diferenças significativas no reacúmulo de placa entre as escovas analisadas.

Haffajee e colaboradores (2001) avaliaram, por meio de parâmetros clínicos, a eficácia de escovas manuais e elétricas. Os resultados demonstraram que ambas reduzem a profundidade de sondagem, o índice de placa e o sangramento à sondagem. Laher e colaboradores (2003), avaliaram a efetividade de 4 escovas manuais e determinaram se a preferência do paciente tem influência no controle de placa em pacientes que utilizavam aparelho ortodôntico fixo. As escovas avaliadas foram Ortodôntica Oral-B, Oral-B Advantage 30, Colgate Precision e Aquafresh. Os resultados mostraram que os índices de placa (IP) e gengival (IG) foram relativamente menores com o uso das escovas em relação ao índice inicial. Não houve diferença significativa entre a média do IP antes e depois do uso de cada escova, assim como em relação à média do índice de placa. Contudo, foi verificada uma pequena diferença na média do IG entre a Colgate Precision e Aquafresh. Não houve diferença significativa na média do IG antes e depois do uso da escova, assim como a preferência do paciente não influenciou o grau de higiene.

\section{Cerdas}

As cerdas são os componentes mais importantes das escovas dentárias, por entrar em contato direto com os tecidos bucais. São elas que determinam as principais características das escovas, como rigidez, durabilidade e eficiência na remoção do biofilme. Uma das características das cerdas é a flexibilidade, que proporciona um melhor acesso às superfícies interdentárias, bem como a rigidez ideal que permite uma boa higiene dentária sem provocar danos aos tecidos bucais. Esses são os requisitos que devem ser encontrados nas cerdas de escovas dentárias, aliadas a uma boa durabilidade. As cerdas podem ser duras, médias, macias ou extra-macias, dependendo da espessura. O diâmetro varia de 0,16 a $0,22 \mathrm{~mm}$ para as macias, 0,23 a $0,29 \mathrm{~mm}$ para as médias e 0,30 ou mais para as duras. As cerdas extra-macias preenchem todos esses requisitos, sendo o tipo mais indicado para pacientes infantis (ARDENGHI et al., 2005).

A ponta dessas cerdas também pode variar, assumindo formas cortadas, bulbosas ou arredondadas. O seu arranjo em tufos pode assumir diferentes configurações: retos, serrilhados, alternados curtos e longos, multidirecionais, inclinados ou ondulados. O seu comprimento deve ser uniforme para permitir um contato e ação simultânea de todas as cerdas da escova, bem como uma pressão uniforme. Atualmente, as cerdas das escovas dentárias são feitas de nylon, devido à sua superioridade em relação às cerdas naturais, quanto à impermeabilidade, resistência à fratura, tamanho uniforme e homogeneidade do material (PERUCHI et al., 2001). O diâmetro das fibras de nylon, por ser mais regular, resulta em cerdas mais arredondadas, o que evita danos aos tecidos bucais, bem como sua deformação (ARDENGHI et al., 2005).

A literatura consultada mostra que escovas com diferentes tipos de cerdas apresentam resultados distintos quando se avaliam a remoção do biofilme e potencial de lesão aos tecidos bucais. Observa-se que as cerdas duras e médias removem melhor o biofilme da superfície dental quando comparadas às do tipo macia, contudo, causam maiores danos ao tecido gengival, como a abrasão (CARVALHO, 2007; ZANATTA, 2011).

As extremidades das cerdas da escova dentária além de serem arredondadas, não devem apresentar achatamentos, dilacerações e farpas, a fim de prevenir danos aos tecidos gengivais e dentários (LOPES; NASCIMENTO, 1993; SANTOS et al., 2002; PERUCHI et al., 2001).

De acordo com Peruchi e colaboradores (2001), a maioria das escovas infantis comercializadas no Brasil apresenta uma tendência para o arredondamento das cerdas. Os autores também consideraram que ainda é necessário melhorar o processo de fabricação, na tentativa de diminuir restos de filamentos e arestas cortantes. Para Santos et al. (2002), no mercado nacional não há nenhum tipo de escova com todas as cerdas arredondadas, embora a maioria destas apresente este tipo de cerda.

Cunha (1993) avaliou o desempenho clínico de duas marcas comerciais de escovas dentárias quanto à sua eficiência na remoção de placa, sem empregar técnicas de escovação orientada e sem modificar hábitos alimentares e higiênicos das crianças participantes. Os autores concluíram que existe uma redução na eficiência de remoção de placa bacteriana com o avançar do estudo, independentemente do sexo e da escova utilizada. Porém, essa diferença é mais evidenciada entre o índice de placa (IHO-S) inicial e a primeira semana de avaliação. Os autores observaram também uma maior remoção de placa bacteriana nos dentes anteriores que nos dentes posteriores, em ambos os sexos, independentemente da escova utilizada.

Bastos (1995) avaliou a eficácia de duas escovas dentárias, sendo uma convencional e a segunda com o atrativo de mudança de cor durante a utilização, com regimes de higiene bucal sem e com instrução e supervisão de escovação (IHO) em crianças entre 10 e 12 anos de idade. Concluiu que a escova que muda de cor, associada à IHO, demonstrou, em 60 dias, maior efeito motivacional nas crianças.

Kilicoglu, Yildirim e Polater (1997) compararam uma escova manual convencional e uma com cabeça desenvolvida para pacientes que utilizavam aparelho ortodôntico 
fixo, quanto à remoção de placa bacteriana e manutenção da saúde periodontal. Os autores concluíram que a escova, especialmente desenvolvida para pacientes com aparelho ortodôntico fixo, não foi superior à escova convencional, uma vez que não foram verificadas diferenças significativas entre os índices, antes e após o uso das escovas.

\section{Cabeça}

É a parte das escovas que sustenta os tufos de cerdas. Deve apresentar um tamanho compreendido entre 25 e $32 \mathrm{~mm}$, com 8 a $11 \mathrm{~mm}$ de largura, contendo 3 x 6 ou 3 × 8 fileiras de tufos, o que corresponde às escovas de tamanho médio ou pequeno. Para crianças, o tamanho indicado é o pequeno que deve abranger dois a três dentes adjacentes. É importante salientar que a cabeça da escova deve ser suficientemente pequena para que as crianças possam alcançar todos os dentes e as bordas gengivais. Além disso, a cabeça deve se situar no longo eixo do cabo. Quanto ao formato, existem diversos tipos no mercado brasileiro desde arredondados até triangulares (DEAN; HUGHES, 1995). Entretanto, não existe uma especificação recomendada e os trabalhos encontrados na literatura não demonstram diferenças na efetividade de remoção do biofilme entre os diferentes tipos (ARDENGHI et al., 2005).

\section{Haste}

É o componente que liga o cabo à cabeça das escovas. Geralmente, são retas ou anguladas. A ADA recomenda o uso de escovas com hastes retas, o que permite um contato regular das cerdas com toda a superfície dentária (ARDENGHI et al., 2005).

Thevissen, Quirynen e Van Steenberghe (1987) afirmam que os diferentes tipos de escovas dentais provavelmente requerem diferentes técnicas de escovação, e ao comparar a eficiência das escovas convexas com as convencionais na remoção de placa, estes autores obtiveram resultados semelhantes.

\section{Cabo}

É o componente responsável pela sustentação da cabeça e manuseio da escova, fato importante quando se trata de pacientes infantis. $\mathrm{O}$ cabo deve ter uma forma retangular ou achatada, a fim de permitir melhor apoio, particularmente quando são adotadas técnicas de escovação com movimentos verticais ou de rotação. Além disso, deve ser reto e volumoso, para facilitar a empunhadura e o acesso à cavidade bucal.

$\mathrm{Na}$ escolha da escova, deve-se considerar se a higienização será feita pelo responsável ou pela criança, de acordo com a idade desta. Para crianças menores (abaixo de 6 anos), situação na qual o adulto realiza a escovação, são indicadas escovas de cabo longo, em torno de dez a treze centímetros, que proporcionam uma boa empunhadura por parte do responsável. No caso de crianças que realizam a própria escovação, deve-se indicar escovas com cabos menores, mais espessos e emborrachados, para facilitar a apreensão (ARDENGHI et al., 2005).

Mestrinho, Carvalho e Figueiredo (1994) realizaram um estudo com 16 escovas em crianças de 4 a 6 anos de idade com índice ceo-s igual a zero. Por meio da análise de escovações realizadas pelo profissional, sem uso de dentifrício, os autores concluíram que não há diferença significativa entre os diversos tipos de escova quanto à remoção de placa bacteriana. $\mathrm{O}$ importante é que o profissional saiba indicar a escova que melhor se adeque à condição bucal e motora do paciente, por meio da observação clínica e relato dos pais sobre as dificuldades apresentadas durante a higienização.

\section{Diferenças entre escovas dentárias manual e elétrica}

A escolha de uma escova de dente depende de fatores como preferência pessoal, custo e recomendação profissional. Em relação às escovas elétricas, estas podem ser mais atrativas para algumas pessoas por representarem uma solução moderna para os problemas do cotidiano. As escovas elétricas foram introduzidas comercialmente no início dos anos 60, como uma alternativa aos métodos manuais de escovação, uma vez que simulam os movimentos exercidos pelo operador quando utiliza uma escova manual (CROSS, 1962; HEANUE et al., 2003). As mais comuns exibem trajetórias laterais e rotatórias da cabeça sendo que, mais recentemente, foram introduzidas no mercado escovas elétricas com uma grande combinação de movimentos, como oscilatórios e as que operam com frequências ultra-sônicas (HEANUE et al., 2003).

O uso de escovas elétricas tem se tornado cada vez mais popular em todo o mundo. Com o objetivo de comparar a eficácia e a segurança de escovas elétricas e manuais, especialmente desenvolvidas para crianças, Grossman e Proskin (1997) realizaram um estudo com participantes entre 8 e 12 anos de idade, verificando que o uso da escova elétrica produziu reduções significativamente maiores nos índices de placa, tanto na dentadura decídua quanto na permanente.

Borutta (1997) avaliou a remoção de placa de uma escova manual (Elmex) em comparação a uma escova elétrica (Rowenta), ambas especialmente desenvolvidas para crianças. A análise estatística revelou uma remoção de placa significativamente mais efetiva com ambas as escovas, imediatamente após a primeira escovação e após 1 e 2 semanas, em comparação aos dados iniciais. Também verificou-se que a escova elétrica promoveu uma redução nos índices de placa significativamente maior que a escova manual em todas as áreas dentárias.

Willershausen e Waterman (2001) avaliaram a efetividade de escovas dentárias elétricas e manuais. O presente estudo foi realizado em uma escola de ensino básico onde já era realizado um programa de prevenção da cárie dentária. Os autores concluíram que, em relação à prevenção de cárie e gengivite, as escovas dentárias manuais e elétricas podem ser consideradas igualmente eficientes para crianças com risco indeterminado de cárie. A frequência de episódios de motivação de higiene bucal não mostrou grande influência nos índices observados neste estudo, já que os valores encontrados nos três grupos não foram estatisticamente significantes.

Costa e colaboradores (2001) compararam a efetividade na remoção de placa realizada com escova elétrica e manual. Quinze crianças com dentição decídua e 14 crianças com dentadura mista foram divididas em 2 grupos e aleatoriamente designadas a utilizar escova manual e elétrica. Não houve diferença, estatisticamente significante, na remoção 
de placa quando as escovas foram utilizadas na dentadura mista. No entanto, para a dentição decídua, a escova elétrica promoveu uma significante remoção de placa da superfície lingual dos dentes.

\section{Objetivos}

Avaliar as escovas dentais mais eficazes, considerando aspectos relacionados às características do cabo em relação à haste e à cabeça, bem como as características das cerdas, levando em conta tamanho e disposição dos tufos; Comparar a eficácia das escovas manuais e elétricas.

\section{Metodologia}

O projeto de pesquisa foi cadastrado na Plataforma Brasil para avaliação ética e aprovado, recebendo o CAAE $n^{\circ}$ 32831014.7.0000.0109.

Um documento sobre a realização da pesquisa, sua metodologia e procedimentos que seriam realizados foi encaminhado aos responsáveis pelas crianças nascidas nos anos de 2006 e 2007, que se encontram matriculadas em uma escola municipal de Umuarama-PR, juntamente com o Termo de Consentimento de Livre Esclarecimento (TCLE), totalizando 45 famílias. As crianças cujos pais assinaram o TCLE foram avaliadas para a determinação da amostra.

Foram selecionadas 30 crianças na faixa etária entre 7 e 8 anos de idade, que não apresentaram dificuldades de compreensão ou limitações de ordem motora, as quais foram avaliadas com relação à capacidade de realização da técnica de escovação proposta por Fones (ARTIGAS, IBARA, 2003). Após a seleção da amostra, foram testados diferentes tipos de escovas dentárias com relação à eficácia na remoção de biofilme dental.

Foram escolhidos 4 tipos de escovas dentais: escova de haste reta (Figura 01) com cerdas regulares, macia- (Tek Júnior, Johnson \&Johnson ${ }^{\circledR}$ - Brasil); escova de haste angulada (Figura 02) com cerdas regulares, macia - (Colgate classic Infantil, Colgate-Palmolive ${ }^{\circledR}$ industrial LTDA - Brasil); escova de haste angulada (Figura 03) com cerdas irregulares, extra macia - (Colgate Ultimate spider- man, Colgate-Palmolive ${ }^{\circledR}$ industrial LTDA - China) e escova elétrica (Figura 04) com cerdas regulares (Figura 08) - (Oral- B ${ }^{\circ}$ Stages power, Dongguan Weihang electrical products Co. LTDA - China). Para tanto, foi realizado um índice de higiene oral (Índice de Higiene Oral Simplificado - IHOS) e o cálculo da percentagem de biofilme presente na cavidade bucal (considerando o IHOS $=3$ como $100 \%$ de presença de biofilme), antes e após a realização da escovação, os quais foram comparados para determinar a eficácia da escovação.
Figura 1: Escova dental com haste reta e cerdas regulares.

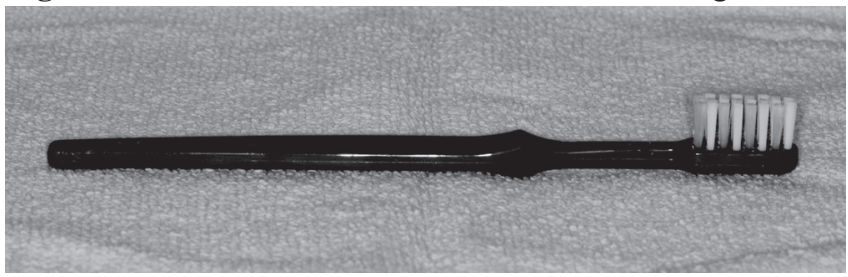

Figura 2: Escova dental com haste angulada e cerdas regulares.

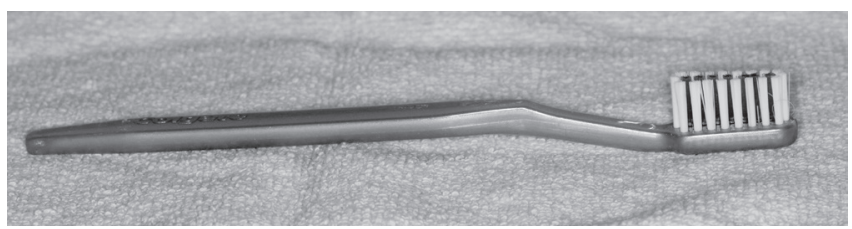

Figura 3: Escova dental com haste angulada e cerdas irregulares.

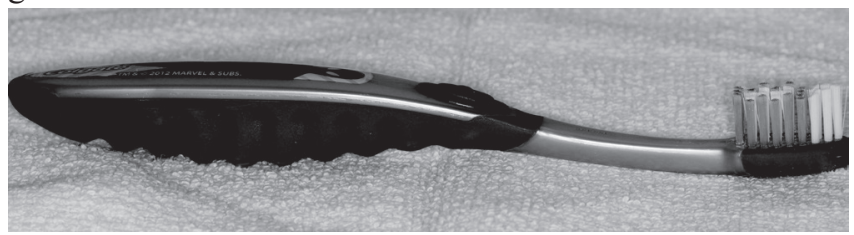

Figura 4: Escova dental elétrica com haste reta e cerdas regulares.

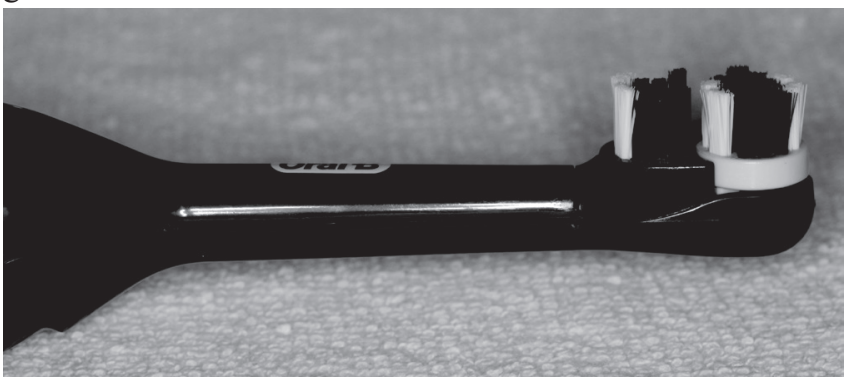

Inicialmente, a evidenciação do biofilme bucal foi realizada por meio de solução evidenciadora à base de fucsina (Eviplac $($ - Brasil) com auxílio de cotonetes, e em seguida a determinação do IHOS, por um único examinador com a ajuda de um anotador, e o cálculo do percentual de biofilme. Dando continuidade, as crianças receberam orientações sobre como realizar corretamente a escovação dentária por meio da demonstração em macromodelos da técnica proposta por Fones, para as escovas manuais e instrução específica para a utilização da escova elétrica. Após a realização da escovação dentária (durante 5 minutos) associada a um dentifrício comercial infantil (Tandy ${ }^{\circledR}$, Colgate-Palmolive industrial LTDA - Brasil) ou adulto (Sorriso ${ }^{\circledR}$, Colgate-Palmolive industrial LTDA - Brasil), de acordo com sua preferência, foram determinados novamente o IHOS e o percentual de biofilme para que fosse feita a comparação dos resultados antes e após a escovação.

Os diferentes tipos de escovas foram testados com intervalos de 7 dias, sempre seguindo a mesma rotina descrita anteriormente, em local e horário padronizado. O IHOS, bem como o percentual de remoção de biofilme, foram utilizados para determinar a eficácia das escovas com relação à remoção de biofilme dental. 
Os resultados foram tabulados no programa Excel 2011 e a análise descritiva desenvolvida por meio do processamento dos dados, fornecendo tabelas e gráficos de frequência absoluta e percentual.

\section{Resultados}

Dos 45 indivíduos previamente selecionados para a participação no estudo, de acordo com o ano de seu nascimento (2006 e 2007), foram selecionados 30. Entretanto, apenas 28 concluíram todas as etapas de avaliação, compondo, portanto, a amostra final.

Como se pode observar na figura5, dentre os indivíduos analisados, houve um predomínio do gênero feminino, que representou $68 \%$.

Figura 5: Distribuição percentual das crianças selecionadas, com relação ao gênero.

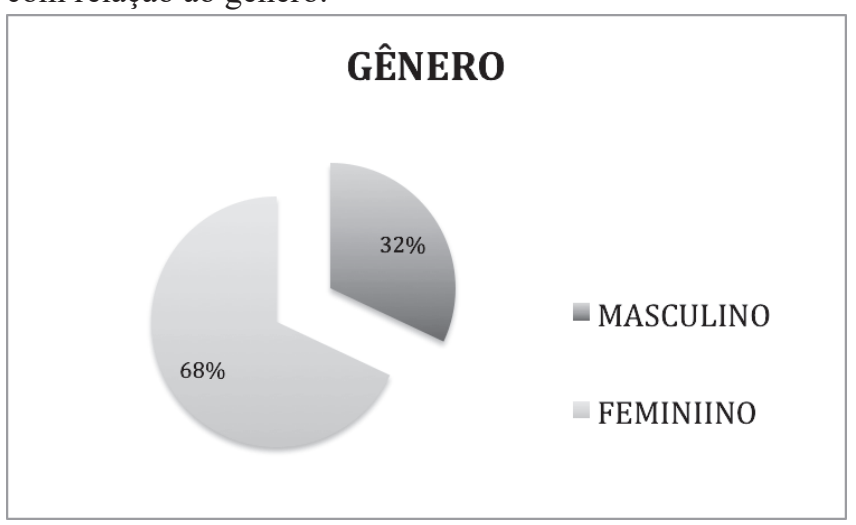

Para a análise dos dados apresentados na tabela 1, foi considerada a diferença encontrada nos resultados obtidos em cada exame, de acordo com o tipo de escova avaliada. Foi realizado o IHOS antes da escovação dentária, que serviu de parâmetro para o cálculo do percentual de biofilme presente nas superfícies dentárias. Após a escovação, o índice foi refeito, permitindo a determinação de um novo percentual. Os percentuais foram comparados e a diferença observada entre o inicial (antes da escovação) e o final (após a escovação) foi o valor considerado para a análise dos resultados apresentados. Para confeccionar a presente tabela, os resultados das diferenças entre os percentuais de biofilme foram segmentados a cada $20 \%$.

A tabela 1 mostra que a eficácia da escova na remoção do biofilme bucal pode ser alterada, de acordo com as características da escova utilizada.
Tabela 1: Número e percentual de indivíduos, de acordo com a redução do cálculo do percentual de biofilme, quando considerada a diferença dos resultados obtidos antes a após a escovação dentária, de acordo com o tipo de escova utilizada.

\begin{tabular}{c|c|c|c|c|c|c|c|c}
\hline & \multicolumn{2}{|c|}{ Haste reta } & \multicolumn{2}{c|}{$\begin{array}{c}\text { Haste } \\
\text { angulada }\end{array}$} & \multicolumn{2}{c|}{$\begin{array}{c}\text { Cerdas } \\
\text { irregulares }\end{array}$} & \multicolumn{2}{c}{ Elétrica } \\
\hline & $\mathrm{n}^{\mathrm{o}}$ & $\%$ & $\mathrm{n}^{\mathrm{o}}$ & $\%$ & $\mathrm{n}^{\mathrm{o}}$ & $\%$ & $\mathrm{n}^{\mathrm{o}}$ & $\%$ \\
\hline 0 a $20 \%$ & 2 & 7,1 & 4 & 14,3 & 2 & 7,1 & 4 & 14,3 \\
\hline 21 a $40 \%$ & 7 & 25,0 & 5 & 17,9 & 8 & 28,6 & 11 & 39,3 \\
\hline 41 a $60 \%$ & 7 & 25,0 & 13 & 46,4 & 11 & 39,3 & 8 & 28,6 \\
\hline 61 a $80 \%$ & 11 & 39,3 & 5 & 17,9 & 6 & 21,4 & 4 & 14,3 \\
\hline 81 a $100 \%$ & 1 & 3,6 & 1 & 3,6 & 1 & 3,6 & 1 & 3,6 \\
\hline TOTAL & 28 & 100 & 28 & 100 & 28 & 100 & 28 & 100 \\
\hline
\end{tabular}

A escova que apresenta a haste reta teve prevalência de $61 \%$ a $80 \%$ de redução do percentual de biofilme, correspondendo a $39,3 \%$ da amostra, contudo outros $25 \%$ apresentaram redução do percentual na faixa de 41 a $60 \%$. Portanto, pode-se considerar que a escova de haste reta apresenta um bom potencial de remoção de biofilme, já que cerca de $68 \%$ dos indivíduos avaliados conseguiram remover mais do que $40 \%$ do biofilme que estava presente em seus dentes.

A escova que apresenta a haste angulada teve prevalência de $41 \%$ a $60 \%$ de redução do percentual de biofilme, correspondendo a $46,4 \%$ da amostra, contudo outros $17,9 \%$ apresentaram redução do percentual na faixa de 61 a $80 \%$. Pode-se considerar que a escova de haste angulada apresenta um bom potencial de remoção de biofilme, já que $67,9 \%$ dos indivíduos avaliados conseguiram remover mais do que $40 \%$ do biofilme que estava presente em seus dentes, porém, quando comparada à escova de haste reta na faixa de $61 \%$ a $80 \%$, apresenta resultados inferiores.

A escova que apresenta as cerdas irregulares também teve prevalência de $41 \%$ a $60 \%$ de redução do percentual de biofilme, correspondendo a 39,3\% da amostra, contudo outros 28,6\% apresentaram redução do percentual na faixa de 21 a 40\%. Portanto, pode-se considerar que a escova de cerdas irregulares apresenta potencial de remoção de biofilme, já que $64,3 \%$ dos indivíduos avaliados conseguiram remover mais que $40 \%$ do biofilme que estava presente em seus dentes. Entretanto, quando comparada às escovas de haste reta $\mathrm{e}$ angulada, percebe-se que o percentual de remoção na faixa de $21 \%$ a $40 \%$, é maior, o que demonstra uma tendência a remover menos biofilme.

A escova elétrica teve prevalência de $21 \%$ a $40 \%$ de redução do percentual de biofilme, correspondendo a 39,3\% da amostra, contudo outros $28,6 \%$ apresentaram redução do percentual na faixa de 41 a $60 \%$. Portanto, pode-se considerar que a escova elétrica apresenta um potencial de remoção de biofilme reduzido, quando comparada aos demais tipos de escova, já que apenas $46,5 \%$ dos indivíduos avaliados conseguiram remover mais do que $40 \%$ do biofilme que estava presente em seus dentes.

Para a análise dos dados apresentados na tabela 2, consideramos a diferença encontrada nos resultados do IHOS obtido antes e depois da escovação dentária, de acordo com o tipo de escova avaliada. $\mathrm{O}$ intuito foi verificar a quantidade de biofilme removida e uma possível mudança na classificação do índice, verificando se houve melhora na qualidade da 
escovação.

Tabela 2: Número e percentual de indivíduos, de acordo com o IHOS apresentado antes e após a escovação dentária, considerando o tipo de escova utilizada.

\begin{tabular}{l|l|c|c|c|c|c|c}
\hline \multicolumn{2}{c|}{} & \multicolumn{2}{|c|}{ Fraco } & \multicolumn{2}{c|}{ Regular } & \multicolumn{2}{c}{ Bom } \\
\cline { 3 - 8 } \multicolumn{2}{c|}{} & $\mathrm{n}^{\mathrm{o}}$ & $\%$ & $\mathrm{n}^{\mathrm{o}}$ & $\%$ & $\mathrm{n}^{\mathrm{o}}$ & $\%$ \\
\hline \multirow{3}{*}{ Haste Reta } & Antes & 22 & 78,6 & 6 & 21,4 & 0 & 0,0 \\
\cline { 2 - 8 } & Depois & 2 & 7,1 & 17 & 60,7 & 9 & 32,1 \\
\hline \multirow{2}{*}{$\begin{array}{l}\text { Haste } \\
\text { Angulada }\end{array}$} & Antes & 21 & 75,0 & 7 & 25,0 & 0 & 0,0 \\
\cline { 2 - 8 } & Depois & 3 & 10,7 & 21 & 75,0 & 4 & 14,3 \\
\hline \multirow{2}{*}{$\begin{array}{c}\text { Cerdas } \\
\text { Irregulares }\end{array}$} & Antes & 22 & 78,6 & 6 & 21,4 & 0 & 0,0 \\
\cline { 2 - 8 } & Depois & 2 & 7,1 & 19 & 67,9 & 7 & 25,0 \\
\hline \multirow{2}{*}{\begin{tabular}{l} 
Elétrica \\
\cline { 2 - 8 }
\end{tabular}} & Antes & 23 & 82,1 & 5 & 17,9 & 0 & 0,0 \\
\cline { 2 - 8 } & Depois & 2 & 7,1 & 24 & 85,7 & 2 & 7,1 \\
\hline
\end{tabular}

Segundo os dados presentes na tabela 2, em todas as análises houve um predomínio da classificação "Fraco", antes da escovação. $\mathrm{O}$ mesmo foi observado em relação à classificação "Regular", após a escovação.

$\mathrm{Na}$ avaliação da escova de haste reta, os indivíduos apresentaram um maior percentual de classificação "Fraco" do índice, antes da escovação (78,6\%). Após a escovação, observou-se a prevalência da classificação "Regular", representando $60,7 \%$ da amostra, seguida pela classificação "Bom", representada por 32\%. O mesmo padrão em relação à mudança de classificação do IHOS foi observado na escova que apresenta a haste angulada, entretanto, um percentual maior (75\%) foi observado na classificação "Regular", após a escovação. Isso nos leva a afirmar que a escova de haste reta apresenta resultados mais satisfatórios, pois, aproximadamente 93\% dos indivíduos apresentaram índices de regular a bom, entretanto a diferença presente nos resultados da classificação "Bom" equivale a mais do que o dobro da escova de haste angulada.

A escova de cerdas irregulares apresentou resultados com comportamento parecido aos da escova de haste reta, entretanto, a classificação "Bom" após a escovação foi atingida por um percentual menor de indivíduos (25\%).

A escova elétrica apresentou uma eficácia reduzida na remoção do biofilme bucal, pois apenas 7,1\% dos indivíduos apresentou a classificação "Bom" após a escovação. Contudo, devido aos $85,7 \%$ da amostra que apresentaram a classificação "Regular", seus resultados não podem ser considerados insatisfatórios.

\section{Discussão}

A prevenção da doença cárie e periodontal, que são respectivamente as duas doenças que mais acometem a cavidade bucal, são metas ainda a serem alcançadas pela odontologia contemporânea (AXELSSON, et al. 1991). Para alcançar esse objetivo, é necessário um bom controle do biofilme dental, com o auxílio de vários instrumentos de higiene bucal, sendo que, até o momento, não existe melhor recurso para tal do que os mecânicos, dentre eles tendo a escova dental como um dos mais importantes (MOREIRA et al, 2010; FEITOSA et al, 2008; LASCALA E MOUSSALLI, 1995).
Ainda considerando que alguns fatores são decisivos para o sucesso do controle de biofilme dental pelo uso da escova dental, como motivação e reforço contínuo, neste trabalho foi realizada a instrução de higiene oral das crianças no decorrer da avaliação dos diferentes tipos de escovas, efetuados por meio da demonstração de técnica de escovação em macromodelos e evidenciação do biofilme dental, conforme realizado por Roslindo et al (1991), Perry e Schimid (1997) e Kather e Candelaria (1999). Entretanto, Felippini e colaboradores (2009) afirmam que os voluntários não deveriam receber instrução de higiene oral neste tipo de avaliação, tendo como justificativa que a redução do índice fosse devido à escova e não ao aperfeiçoamento da técnica, pois como afirmam Scheidegger e Lussi (2005) o índice de placa em crianças pode ser melhorado com instruções para uma boa escovação, independentemente do tipo de escova utilizada. Em nosso estudo, como não tínhamos contato prévio com os voluntários, não sabíamos nenhuma informação sobre seus conhecimentos a respeito das técnicas de higiene oral. Com base nesta realidade, optamos por fazer a demonstração da técnica no primeiro dia e, para padronizar a análise, repetimos nas demais.

Felippini (2009) avaliando a influência da disposição das cerdas de duas escovas manuais, uma apresentando cerdas na mesma altura e outra com cerdas irregulares não obteve diferenças estatísticas. Claydon (2002) e Sharma (2005) também avaliaram a eficácia e a segurança de duas escovas manuais com diferentes disposições de cerdas e não encontraram diferenças estatisticamente significantes entre elas. No presente estudo, quando comparadas às escovas de haste reta e angulada, que apresentavam cerdas regulares, a escova que possuía cerdas irregulares demonstrou uma tendência a remover menos biofilme quando se considerou a redução de seu percentual. Contudo, na avaliação da classificação do IHOS, apresentou resultados semelhantes às escovas de cerdas regulares.

No estudo de Roscher (2004), avaliando o efeito da motivação e instrução de higiene oral e comparando uma escova manual com uma escova elétrica, em pacientes com doença periodontal, constatou-se grande melhora na remoção de biofilme entre os voluntários durante o período de avaliação, e que a capacidade de impedir o acúmulo melhorou durante o estudo, independentemente da escova usada. Também foi constatado que ocorreu melhora no índice de biofilme após as reorientações de higiene, indicando que isso seria mais importante do que a escolha da escova dentária. Contrariando esses dados, no presente estudo observamos uma grande presença de biofilme nas análises iniciais de todas as etapas, que foram realizadas com intervalos de 7 dias; portanto, não observamos uma redução do acúmulo de biofilme no decorrer da pesquisa. Podemos atribuir este resultado à fase do desenvolvimento em que as crianças avaliadas se apresentam, pois estão na dentição mista.

Costa (2001) avaliou uma escova elétrica e uma escova manual, em crianças com dentição mista e decídua. $\mathrm{Na}$ dentição mista verificou que não houve diferenças significativas em relação à remoção de placa bacteriana com as diferentes escovas, porém a escova de dentes elétrica promoveu significativamente maior remoção de placa bacteriana nas superfícies linguais dos dentes com dentição decídua. No presente estudo, foi observada uma eficácia reduzida da 
escova elétrica quando comparada aos demais tipos avaliados, em relação à capacidade de redução da classificação do IHOS, bem como da redução do percentual de biofilme presente nas superfícies dentárias. Este achado pode ser explicado pelo fato de que a maioria das crianças que fizeram parte da amostra nunca tinham manuseado uma escova elétrica, portanto, não estavam familiarizadas com sua utilização, o que gerou certo receio, mesmo após a instrução de higiene ter sido realizada. Em contrapartida, as crianças estão habituadas a manusear as escovas manuais, rotineiramente. Com base neste achado, observamos a necessidade de estudos longitudinais, avaliando a eficácia das escovas elétricas por crianças que apresentam dentição mista. Em contrapartida, Biavati (2010), avaliou a eficácia na redução do índice de biofilme dental e sangramento gengival utilizando uma escova manual e uma escova elétrica em pacientes ortodônticos e concluiu que a escova elétrica propiciou uma melhora maior no índice de placa e de sangramento do que a escova manual, contudo, vale ressaltar que a faixa etária da amostra era mais elevada.

Segundo alguns autores, tanto a escova manual como a escova elétrica, podem ser usadas e apresentar a mesma eficácia na prevenção da cárie e gengivite. Também, não há diferença significativa na redução de placa utilizando escovas de baixo custo ou uma escova comercial, de custo mais elevado, sendo o fator determinante a correta instrução de escovação, independentemente da escova utilizada (WILLERSHAUSEN; WATERMANN, 2001; PARIZOTTO et al, 2003; FEITOSA et al, 2008; BIAVATI et al, 2010; SCHEIDEGGER; LUSSI, 2005). Ainda, neste âmbito e, considerando o estudo realizado por Feitosa (2008), que avaliou a apresentação comercial de diferentes escovas dentárias no Brasil, verificou-se que houve expressiva variabilidade de preço, de $\mathrm{R} \$ 1,00$ até $\mathrm{R} \$ 8,55$, variação essa que se torna importante considerando as discrepâncias econômicas das classes sociais no Brasil e, também, que a escolha da escova dental, em algumas populações, baseia-se principalmente no preço (LOPES; NASCIMENTO, 1993). Em nosso estudo, também houve uma variação grande dos valores, sendo a diferença de preço entre o modelo de escova mais barato (haste reta) e o mais caro (escova elétrica) foi superior a $\mathrm{R} \$ 30,00$.

Essa informação é relevante devido ao fato de que várias características comerciais podem aumentar o custo dessas escovas, como: corantes nas cerdas, desenhos infantis no cabo, material utilizado na fabricação (que servem como uma estratégia comercial para atrair as crianças) que encarecem o produto e não influenciam diretamente na qualidade da higienização do paciente infantil. O cirurgião dentista deve levar em conta o fator preço no momento de indicar a escova dentária, já que a população carente possui poder aquisitivo limitado para aquisição de escovas muito elaboradas.

Escovas convencionais e de baixo custo são tão eficazes quanto as escovas mais sofisticadas para higiene bucal (Feitosa et al, 2008). No presente estudo, os melhores resultados, independentemente da análise realizada, foram atribuídos à escova mais simples, que possui haste reta, cerdas regulares e menor custo. Em contrapartida, notou-se uma preferência pela escova elétrica por parte dos voluntários. Segundo Aass e Gjermo (2000) “...a escolha pela escova elétrica deve-se a um sentimento subjetivo de melhor capacidade de limpeza...". Entretanto, foi observado ainda que apesar da preferência pela escova elétrica, havia receio na utilização inicial desta, devido à sensação de risco de machucar a gengiva transmitida pela movimentação própria da escova.

Roscher (2004) utilizou em seu estudo apenas um tipo de dentifrício em todos os voluntários, enquanto utilizamos dois tipos, sendo um destinado ao público infantil e outro destinado ao adulto, ficando a escolha a critério do voluntário. Contudo, os dentifrícios selecionados para o presente estudo, apresentavam características semelhantes em relação aos abrasivos de sua composição, para evitar alteração nos resultados.

\section{Considerações Finais}

De acordo com a metodologia empregada no presente estudo e com os resultados obtidos, podemos concluir que todas as escovas dentárias apresentam potencial de redução do biofilme dentário, independentemente das características de sua haste, cerdas ou manuseio (manual ou elétrico). Contudo, os melhores resultados foram atribuídos à escova que apresenta a haste reta, que também possui cerdas regulares.

A escova elétrica apresentou resultados inferiores a todos os tipos de escovas manuais, tanto na diferença do percentual de biofilme presente nas superfícies dentárias antes e após escovação, como na capacidade de melhoria da qualidade de higiene bucal.

A escolha do tipo de escova a ser indicada para cada indivíduo deve ser baseada no bom senso, considerando suas características e dificuldades, poder aquisitivo e potencial motivador. Uma escova infantil mais barata pode ser a opção mais viável, especialmente para populações atendidas pela rede pública de saúde.

\section{Referências}

AASS, A. M.; GJERMO, P. Comparison of oral hygiene efficacy of one manual and two electric toothbrushes. Acta Odontol Scand. v. 58, p. 166-170, 2000.

ARDENGHI, T. M. et al. Controle mecânico do biofilme dental. In: CORREAA, M. S. N. P. Odontopediatria na primeira infância. 2. ed. São Paulo: Santos, 2005. p. 317332.

ARTIGAS, A. L. C.; IBARA, L. Avaliação de diferentes técnicas de remoção de placa bacteriana: uma revisão de literatura. Faculdades Integradas Maria Coelho Aguiar, Porto Velho, v. 2, n. 2, p. 31-44, 2003.

AXELSSON, P.; LINDHE, J.; NYSTROM, B. On the prevention of caries and periodontal disease. J. Clin. Periodontal, v. 18, n. 3, p.182-189, 1991.

BASTOS, E. P. S. Escovação dental: avaliação do tipo de escova sobre o índice de placa bacteriana. 1995. $127 \mathrm{f}$. Tese (Doutorado) - Faculdade de Odontologia, Universidade Federal do Rio de Janeiro, Rio de Janeiro, 2005.

BELLINI, I. L. T.; ARNEBER, P.; VON DER FEHR, F. R. Oral hygiene and caries: a rewiew. Acta odontol. Scand. v. 
39, n. 5, p. 257-265, 1981.

BERENIE, J.; RIPA, L. W.; LESKE, G. The relationship of frequency of toothbrushing, oral hygiene, gingival health, and caries-experience in school children. J. Public Health Dent. v. 33, n. 3, p. 160-171, 1973.

BIAVATI, S. A. et al. Manual orthodontic vs. oscillatingrotating electric toothbrush in orthodontic patients: a randomised clinical trial. European Journal of Paediatric Dentistry, v. 11, n. 4, p. 200-202, 2010.

BORUTTA, A. Plaque removal efficacy of a newly developed powered toothbrush in the primary dentition of pre-school children. J. Clin. Dent. v. 8, n. 6, p. 151-155, 1997.

CARVALHO, R. S. et al. Comparative analysis between hard-and soft filament toothbrushes related to plaque removal and gingival abrasion. J. Clin. Dent. v. 18, n. 3, p. 61-64, 2007.

CLAYDON, N. et al. Comparative professional plaque removal study using 8 branded toothbrushes. J. Clin.

Periodontol, v. 29, n. 12, p. 310-316, 2002.

COSTA, C. C. et al. Plaque removal by manual and electric toothbrushing among children. Pesqui. Odontol. Bras. v. 15, n. 4, p. 293-301, 2001.

CROSS, W. G. A comparative study of tooth cleaning using conventional and electrically operated toothbrushes. Br.

Dent. J. v. 113, n. 1, p. 19-22, 1962.

CUNHA, R. L. F. Avaliação clínica de escovas dentárias na remoção de placa sem técnicas de escovação orientada. 1993. 85 f. Dissertação (Mestrado) - Faculdade de Odontologia, Universidade Federal do Rio de Janeiro, Rio de Janeiro, 1993.

DEAN, J. A.; HUGHES, C. V. Métodos mecânicos e quimioterápicos caseiros de higiene oral. In: McDONALD, R. E.; AVERY, D. R. Odontopediatria. 6. ed. Rio de Janeiro: Guanabara Koogan, 1995. p. 176-194.

FEITOSA, N. B. et al. Avaliação da apresentação comercial de escovas dentais disponíveis no Brasil. Rev. odonto ciênc. v. 23, n. 1, p. 77-81, 2008.

FELIPPINI, A. L. C. et al. A influência da disposição das cerdas de escovas dentais manuais na remoção de placa dental. Braz. Dent. Sci. v. 12, n. 3, p. 20-25, 2009.

GROSSMAN, E.; PROSKIN, H. A comparison of the efficacy and safety of an electric and a manual children's toothbrush. J. Am. Dent. Assoc. v. 128, n. 4, p. 469-474, 1997.

HAFFAJEE, A. D. et al. Efficacy of manual and powered toothbrushes. Effect on clinicalparameters. J. Clin.

Periodontol. v. 28, n. 1, p. 937-946, 2001.
HAlla, D. A propósito das escovas dentárias. Rev. Paul. Odontol. v. 42, n. 2, p. 42-47, 1982.

HEANUE, M. et al. Manual versus powered toothbrushing for oral health. In: The Cochrane Library. Oxford: Update Software, 2003.

KATHER, J. M.; CANDELARIA, L. F. A. Contribuição ao estudo da eficiência de sete escovas dentais em odontopediatria utilizando-se o método de escovação de Stillman modificado. Revista Biociênc. Taubaté, v. 5, n. 2, p. 41-49, jul./dez. 1999.

KILICOGLU, H.; YILDIRIM, M.; POLATER, H. Comparison of the effectiveness of two types of toothbrushes on the oral hygiene of patients undergoing orthodontic treatment with fixed appliances. Am. J.

Orthod. Dentofacial Orthoped. v. 111, n. 6, p. 591-594, 1997.

LAHER, A.; KROON, J.; BOOYENS, S. J. Effectiveness of four manual toothbrushes in a cohort of patients undergoing fixed orthodontic treatment in an academic training hospital. SADJ, v. 58, n. 6, p. 234-237, 2003.

LASCALA, N. T.; MOUSSALLI, N. T. Higienização bucal. In: Compendio terapêutico periodontal. 2. ed. São Paulo: Artes Médicas, 1995. Cap.12, p. 239-269.

LOE, H.; THEILADE, E.; JENSEN, S. B. Experimental gingivitis in man. J. Periodontol. n. 36, n. 1, p. 177-187, 1965.

LOPES, W. C.; NASCIMENTO, Z. C. P. Avaliação da preferência, uso e substituição de escovas dentais. ROBRAC, v. 3, n. 9, p. 4-10, 1993.

MESTRINHO, H. D.; CARVALHO, J. C.; FIGUEIREDO, C. S. Desempenho clínico das escovas infantis produzidas no Brasil. Rev. Gaúcha Odontol. v. 42, n. 5, p. 254-258, 1994.

MOREIRA, V. G. et al. Parâmetros morfológicos de escovas dentais comercializadas em João Pessoa- PB. Int. J. Dent. Recife, v. 9, n. 4, p. 169-173, out./dez. 2010.

PANZERI, H. et al. Avaliação de algumas características das escovas dentais do mercado nacional. Rev. ABO Nac. v. 1, n. 1, p. 23-29, 1993.

PARIZOTTO, S. P. C. de O. L. et al. Effectiveness of low cost toothbrushes, with or with out dentifrice, in the removal of bacterial plaque in deciduous teeth. Pesqui. Odontol Bras. v. 17, n. 1, p. 17-23, 2003.

PERRY, D. A.; SCHIMID, M. O. Controle de placa. In: CARRANZA JUNIOR, F. A.; NEWMAN, M. G. Periodontia clinica. 8. ed. Rio de Janeiro: Guanabara Koogan, 1997. p. 522-538.

PERUCHI, C. et al. Características das cerdas das escovas 
infantis comercializadas no Brasil. ROBRAC, v. 10, n. 30,

ROSCHER, T. et al. Effect of instruction and motivation in the use of electric and manual toothbrushes in periodontal patients. A comparative study. Braz. Oral Res. v. 18, n. 4, p. 296-300, 2004.

ROSLINDO, N. C. et al. Estudo histomorfológico da mucosa do sulco gengival após a aplicação de algumas soluções evidenciadoras de placa bacteriana dental. Revista Fac. Odon. Lins, v. 4, n. 1, p. 23-28, jan./jun. 1991.

SANTOS, F. A. et al. Avaliação das características das extremidades da cerdas de escovas dentárias de diferentes marcas adquiridas no mercado nacional. RPG, v. 9, n. 2, p. 109-115, 2002.

SCHEIDEGGER, N.; LUSSI, A. Tooth cleaning with different children's toothbrushes: a clinical study. Schweiz Monatsschr Zahnmed, v. 2, n. 1, p. 100-106, 2005.

SHARMA, N. C. et al. Plaque removal efficacy and safety of the next generation of manual toothbrush with angled bristle technology: results from three comparative clinical studies. Am. J. Dent. v. 18, n. 1, p. 3-7, 2005.

STORINO, S. P. Pacientes portadores de aparelho ortodôntico. In: _. Odontologia preventiva especializada. Rio de janeiro: Cultura médica, 1994. p. 21-25.

STABBE, K. A. et al. A comparation de plaque reaccumulation and patient acceptance using a conventional toothbrush and a newly designed toothbrush. Clin. Prev.

Dent. v. 10, n. 5, p. 10-14, 1988.

THEVISSEN, E.; QUIRYNEN, M.; VAN

STEENBERGHE, D. Plaque removing effect of a convexshaped brush compared with a conventional flat brush. $\mathbf{J}$. Period. v. 58, n. 12, p. 861-867, 1987.

WAERHAUG, J. Effect of toothbrushing on subgingival plaque formation. J. Periodontol. v. 52, n. 1, p. 30-34, 1981.

WILERSHAUSEN, B.; WATERMANN, L. Longitudinal study to assess the effectivity of electric and manual toothbrushes for children. Eur. J. Med. Res. v. 6, n. 1, p. 39-45, 2001.

VILANI, E.; BAPTISTA, T. C. L.; VERTUAN, V. Avaliação clínica da efetividade de escovas dentais. RGO, v. 46, n. 1 , p. $217-21,1998$.

ZANATTA, F. B. et al. Biofilm removal and gingival abrasion with and soft toothbrushes. Oral Health Prev. Dent. v. 9, n. 1, p. 177-183, 2011. 